\title{
Alat Peraga Digital Pengenalan Pahlawan Sulawesi Utara
}

\author{
Feiby Marlin Pongoh ${ }^{(1)}$, Alicia A. E. Sinsuw ${ }^{(2)}$, Virginia Tulenan ${ }^{(3)}$ \\ Teknik Informatika, Universitas Sam Ratulangi, Manado, Indonesia. \\ Email: feibypongoh@gmail.com, aliciasinsuw@yahoo.com, virginia.tulenan@gmail.com
}

\begin{abstract}
Abstrak --- Pembelajaran pada saat ini sangat didukung oleh peran teknologi. Berbagai media pembelajaran terus bermunculan seiring dengan berkembangnya teknologi yang semakin pesat. Begitu juga dengan proses pembelajaran yang dilakukan oleh anak khususnya yang berusia 4-10 tahun dimana mereka cenderung lebih menginginkan pembelajaran dengan konsep yang menarik biasanya berupa alat peraga yang bersifat permainan, agar dapat meningkatkan ketertarikan anak dalam proses pembelajaran. Karena anak-anak lebih tertarik melakukan pembelajaran dengan menggunakan alat peraga maka dibuat alat peraga yang berupa permainan puzzle. Tujuan pembuatan alat peraga ini untuk mengenalkan Pahlawan dari Sulawesi Utara kepada anak usia 4-10 tahun. Permainan dikembangkan dengan menggunakan Game Engine Unity 3D pada platform yang berbasis desktop dengan tema Pahlawan. Metodologi yang digunakan dalam membuat aplikasi ini menggunakan Metode Pemrograman Ekstrem dan perancangan aplikasi menggunakan Unified Modelling Language. Kelebihan dari aplikasi alat peraga ini yaitu penggunaannya mudah dan dapat di mengerti oleh usia anak-anak. Setiap puzzle Pahlawan yang dimainkan akan memberikan informasi tentang biografi tentang Pahlawan tersebut jika permainan puzzle telah tersusun.
\end{abstract}

Kata Kunci : Puzzle, Alat Peraga, Pahlawan, Unity 3D, Anak-anak

\section{PENDAHULUAN}

Media pembelajaran pada zaman sekarang ini tidak lepas dari peran teknologi yang semakin berkembang. Pembelajaran bukan hanya dilakukan di dalam lingkup sekolah, melainkan dimulai dari lingkup paling kecil yaitu keluarga dan berkembang sampai pada lingkup masyarakat. Dalam proses pembelajaran khususnya untuk anak-anak, sekarang ini banyak metode yang digunakan mulai dari menjelaskan secara langsung kepada anak sampai dengan menggunakan alat peraga yang memiliki bentuk khusus agar dapat membantu terjadinya proses pembelajaran.

Alat peraga khusus untuk anak biasanya dalam bentuk permainan, karena selain untuk membantu proses belajar, anak dapat bermain serta bisa mengembangkan diri, melatih indera dan membantu otak anak dalam berpikir. [2]

Salah satu permainan yang sering dipakai sebagai alat dalam proses pembelajaran anak adalah puzzle. Permainan puzzle dapat dimainkan oleh anak sebagai media atau alat peraga edukatif untuk proses pembelajaran dan pengembangan diri seorang anak. Konten pembelajaran bermacam- macam, namun penulis ingin mengangkat tentang Pengenalan Pahlawan, khususnya Pahlawan dari daerah Sulawesi Utara sehingga bisa menanamkan pengetahuan sejak dini tentang Pahlawan dan jasa-jasanya terhadap kemerdekaan sekaligus mengenalkan Pahlawan kepada anak-anak.

\section{II.LANDASAN TEORI}

\section{A. Pengertian Alat Peraga}

Alat peraga merupakan bagian dari media pembelajaran yang diartikan sebagai semua benda (dapat berupa manusia, objek atau benda mati) sebagai perantara yang dapat digunakan dalam proses pembelajaran. Tujuan pada prinsip dasar penggunaan media pembelajaran yakni memperjelas instrument yang disampaikan, merangsang pikiran, perhatian serta kemampuan. Dengan demikian media pembelajaran mempunyai fungsi penting dalam memperkenalkan, memperjelas, memperdalam dan memperkaya informasi tentang sesuatu. [2]

\section{B. Multimedia}

Definisi multimedia secara umum adalah penggabungan berbagai infomasi dengan menggunakan fasilitas dari komputer. Multimedia yang berasal dari kata multi yang berarti banyak atau lebih dari satu dan media yang dapat diartikan penyajian suatu tempat. Multimedia adalah pemanfaatan komputer untuk membuat dan menggabungkan teks, audio, gambar, bergerak (video dan animasi dengan menggunakan link dan tool yang memungkinkan pemakaian melakukan navigasi, berinteraksi, berkreasi dan berkomunikasi. Kelebihan multimedia adalah menarik indera dan minat, karena merupakan gabungan antara pandangan, suara dan gerakan. [6]

\section{Unity $3 D$}

Unity adalah sebuah game engine yang memungkinkan pengguna, baik perorangan maupun tim, untuk membuat sebuah game yang dapat digunakan secara gratis. Unity merupakan sebuah engine multiplatform yang memungkinkan game yang di bangun dapat di-publish untuk berbagai platform. Penggunaan engine versi free dibatasi dengan beberapa fitur yang dikurangi atau bonus modul prefab tertentu yang ditiadakan dan hanya tersedia untuk pengguna berbayar.

Unity Engine dapat mengolah beberapa data seperti objek tiga dimensi, suara, teksture, dan lain sebagainya. Unity Engine memiliki kerangka kerja (framework) lengkap untuk pengembangan profesional. Sistem inti engine ini menggunakan beberapa pilihan bahasa pemrogramam, diantaranya C\#, javascript maupun boo. [5]

\section{Pahlawan}

Pahlawan adalah sebuah kata. Secara etimologi kata Pahlawan berasal dari bahasa sansekerta "phala" yang bermakna hasil atau buah. Menurut kamus besar bahasa 
Indonesia Pahlawan berarti orang yang menonjol karena keberanian dan pengorbanannya dalam membela kebenaran pejuang yang gagah berani.

Pahlawan adalah seorang yang pahala yang perbuatannya berhasil bagi kepentingan orang banyak. Perbuatannya memiliki pengaruh terhadap tingkah laku orang lain, karena dinilai mulia dan bermanfaat bagi kepentingan masyarakat bangsa atau umat manusia [3]

\section{E. UML (Unified Modelling Language)}

UML (Unified Modeling Language) adalah bahasa pemodelan untuk sistem atau perangkat lunak yang berparadigma berorientasi objek. Pemodelan sesungguhnya digunakan untuk penyederhanaan permasalahanpermasalahan yang kompleks sedemikian rupa sehingga lebih mudah dipelajari dan dipahami. [1]

\section{F. Pengujian Perangkat Lunak}

Pengujian perangkat lunak adalah elemen kritis dari jaminan kualitas perangkat lunak dan mempresentasikan kajian pokok dari spesifikasi, desain dan pengkodean. Terdapat 2 jenis pengujian perangkat lunak yaitu whitebox testing dan blackbox testing. [4]

\section{G. Metode Perancangan}

Pemrograman Ekstrem merupakan salah satu pendekatan dalam pengembangan perangkat lunak cepat. Pemrograman Ekstrem merupakan suatu pendekatan berorientasi objek sebagai paradigma pengembangan yang diinginkan dan mencakup di dalamnya seperangkat aturan dan praktik-praktik yang terjadi dalam konteks empat kegiatan kerangka kerja yaitu perencanaan, perancangan, pengkodean dan pengujian. Karena perancangan perangkat lunak pada rekayasa perangkat lunak cepat XP hampirhampir tidak menggunakan notasi maka perancangan pada XP dipandang sebagai buatan sementara yang dapat dan harus terus menerus diubah seiring majunya pelaksanaan konstruksi perangkat lunak.

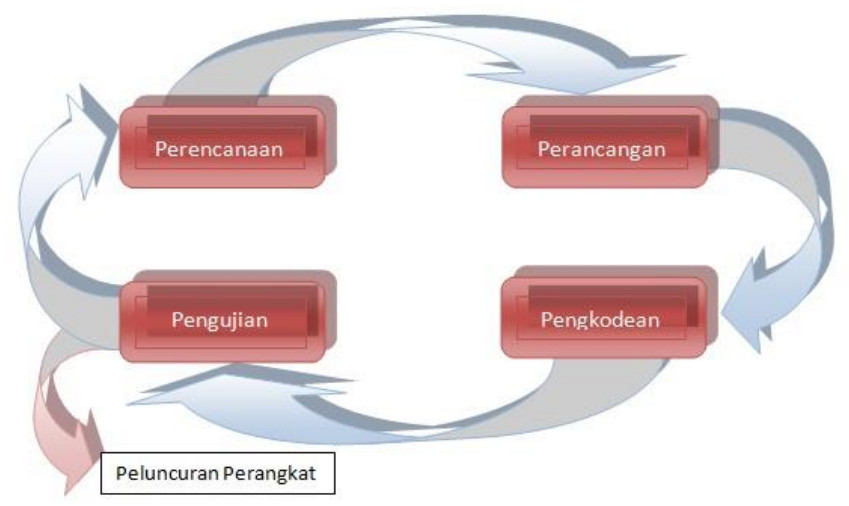

Gambar 1. Proses Pemrograman Ekstrem

Pemrograman Ekstrem merupakan suatu pendekatan berorientasi objek sebagai paradigma pengembangan yang diinginkan dan mencakup di dalamnya seperangkat aturan dan praktik-praktik yang terjadi dalam konteks empat kegiatan kerangka kerja yaitu perencanaan, perancangan, pengkodean dan pengujian. [4]

\section{METODE PENELITIAN}

\section{A. Metodologi Penelitian}

Metodologi penelitian yang digunakan dalam penulisan skripsi ini adalah sebagai berikut :

\section{- Metode Pengumpulan Data}

Untuk menyelesaikan penelitian ini perlu dilakukan pengumpulan data dengan menggunakan beberapa metode. Yang pertama adalah studi literatur yaitu mengumpulkan data melalui referensi karya ilmiah, buku dan internet yang berhubungan dengan tugas akhir, kuisioner dengan mengumpulkan data dari anak-anak dengan memberikan beberapa pertanyaan yang berhubungan dengan aplikasi yang dibuat.

\section{B. Metode Perancangan}

\section{Karakteristik Responden}

Karakteristik responden dalam pembuatan alat peraga ini yaitu responden berjumlah 20 orang dan target dari pembuatan aplikasi alat peraga ini mulai dari usia 4-10 tahun yang terdiri dari 6 anak laki-laki dan 14 anak perempuan dengan rata-rata tingkat pendidikan masih berada dibangku Sekolah Dasar.

\section{Perencanaan}

\section{a) Konsep Game}

Alat peraga ini akan dibuat dalam genre Educational Game dengan mode first-person atau mode dimana pemain akan melihat antar muka dalam sudut pandang orang pertama. Game ini termasuk genre Educational Game karena dengan memainkannya pemain dapat mengetahui dan mendapatkan informasi tentang Pahlawan dan profilnya. Pemain akan memainkan game berupa puzzle atau kepingan gambar dari Pahlawan

b). Teknologi yang digunakan

1. Bahasa pemrograman : $\mathrm{C \#}$

2. .Game engine : Unity $3 D$

3. Sistem Operasi : Windows 8

4. Spesifikasi laptop yang digunakan :

- Processor : AMD C-50 Proccessor 1.00Ghz

- RAM : 2 GB DDR3

- Harddisk : 320 GB

\section{c). Target Pemain}

Ditargetkan alat peraga game ini dimainkan oleh kalangan usia anak-anak dengan batas maximal usia 10 tahun.

\section{d). Keunikan Game}

Keunikan game ini adalah karena game ini dapat memberikan pengetahuan kepada pemainnya mengenai Pahlawan Sulawesi Utara yang telah berjasa bagi bangsa.

\section{e). Target Hardware}

Game ini ditujukan kepada pemain yang memiliki personal computer $(P C)$ atau laptop. 


\section{Perancangan}

\section{a) Storyboard}

Perancangan Storyboard Tampilan Menu Awal dapat dilihat pada gambar 2, dimana pada storyboard terdapat judul game, tombol mulai untuk dapat menjalankan permainan dan memilih pahlawan, tombol info untuk melihat bagaiman cara bermain, dan tombol keluar

\begin{tabular}{|c|c|}
\hline \multicolumn{2}{|l|}{ Multimedia Storyboard } \\
\hline $\begin{array}{l}\text { Project: Pengenalan } \\
\text { Pahlawan Sulawesi } \\
\text { Utara }\end{array}$ & $\begin{array}{l}\text { Date: } \\
\text { 06 Juli } 2015\end{array}$ \\
\hline \multirow[t]{5}{*}{ Screen: 3 of 13} & Screen ID: mainmenu \\
\hline & JUDUL GAME \\
\hline & MULAI \\
\hline & INFO \\
\hline & KELUAR \\
\hline \multirow{2}{*}{\multicolumn{2}{|c|}{$\begin{array}{l}\text { Screen Description: } \\
\text { Rancangan tampilan menu untuk game }\end{array}$}} \\
\hline & \\
\hline $\begin{array}{l}\text { Link From Screen ID: } \\
\text { splashscreen }\end{array}$ & Link to Screen ID: - \\
\hline \multicolumn{2}{|l|}{ Color Scheme: - } \\
\hline \multicolumn{2}{|c|}{ Text Attributes: vanilla 16} \\
\hline \multicolumn{2}{|c|}{$\begin{array}{l}\text { Still Images: background image } \\
\text { menu.jpg (Main) }\end{array}$} \\
\hline
\end{tabular}

Gambar 2. Storyboard Game

b) Diagram UML

Perancangan sistem akan membahas mengenai cara kerja game yang terdiri dari usecase diagram dan activity diagram.

\section{- Use case Diagram}

Use case diagram menggambarkan fungsionalitas yang diharapkan dari sebuah sistem. Sebuah use case merepresentasikan sebuah interaksi antara aktor dengan sistem.

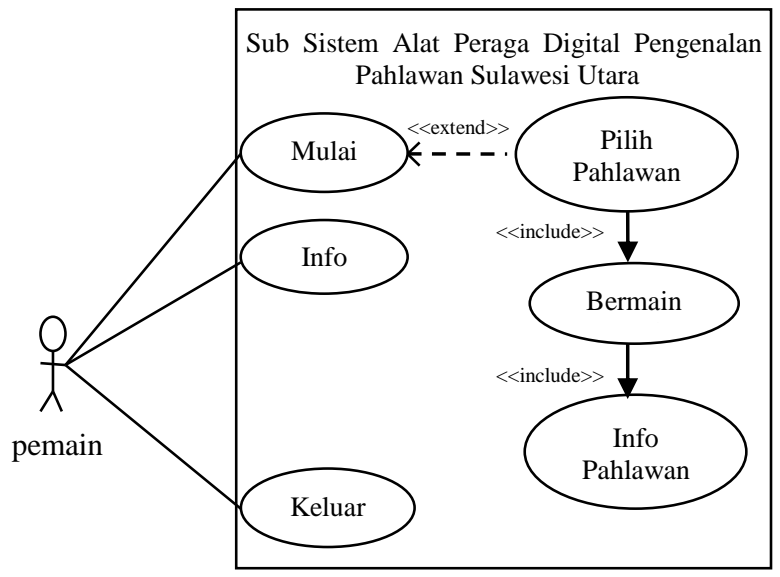

Gambar 3. Usecase diagram

Pada gambar 3 Usecase Diagram pemain dapat mulai menjalankan permainan setelah memilih tombol mulai, setelah memilih tombol mulai pemain dapat memilih pahlawan dan langsung menyuzun puzzle dan melihat info dari pahlawan yang dipilih.

\section{- Activity Diagram}

Pada gambar 4 activity diagram, Pemain pertama kali harus memilih tombol mulai sistem akan menampilkan scene pilih pahlawan untuk memulai bermain, kemudian setelah memilih pahlawan sistem akan langsung mengarahkan pemain untuk menyusun puzzle. Setelah pemain selesai menyusun puzzle secara otomatis informasi puzzle akan di tampilkan sistem, saat pemain menekan tombol Pilih Pahlawan maka sistem akan menampilkan kembali scene pilih pahlawan.

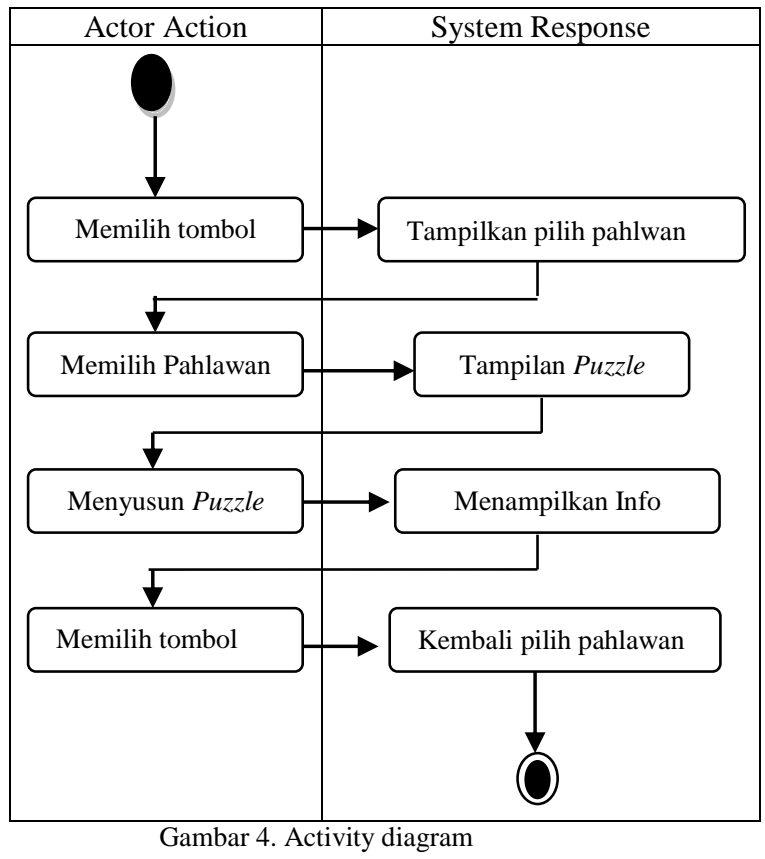

4. Pengkodean

Dalam pembuatan aplikasi pengenalan pahlawan ini, ada serangkaian kode yang digunakan dalam proses pembuatan aplikasi. Disini penulis akan membahas salah satu kode sumber dalam pembuatan aplikasi ini.

Kode Sumber Tampilan Main Menu :

using UnityEngine; using System.Collections;

public class menu : MonoBehaviour \{

$$
\begin{aligned}
& \text { public void OnClickMulai () \{ } \\
& \text { Application.LoadLevel("level"); }
\end{aligned}
$$$$
\text { public void OnClickinfopermainan }()\{
$$$$
\text { Application.LoadLevel("infopermainan"); }
$$

Penulis akan menjelaskan kode sumber diatas yaitu, untuk using UnityEngine dan using System.Collection adalah merupakan library yang terdapat dalam Unity3D yang sudah terpaketkan dalam code apabila akan melakukan 
pengkodean. Public class menu merupakan kode untuk memanggil paket menu agar dapat ditampilkan pada aplikasi. Public void OnClick adalah code yang digunakan untuk membuat suatu tombol dapat berfungsi dengan cara di klik agar dapat berjalan pada aplikasi. Sedangkan untuk Application.LoadLevel adalah code untuk menampilkan scene selanjutnya.

\section{Pengujian}

Dalam proses pengujian penulis memilih menggunakan pengujian kotak hitam. Pengujian kotak hitam berupaya untuk menemukan kesalahan dalam kategori berikut: (1) Fungsi yang salah atau hilang, (2). Kesalahan antar muka, (3). Kesalahan dalam struktur dan data atau akses basis data eksternal, (4). Kesalahan perilaku atau kinerja, (5). Kesalahan Inisialisasi dan penghentian. Ada beberapa test case dalam teknik pengujian kotak hitam tapi dalam penelitian ini penulis hanya akan menggunakan test case pengujian berbasis grafik.

\section{HASIL DAN PEMBAHASAN}

\section{A. Implementasi Antar Muka}

Implementasi antar muka ini merupakan tahapan untuk mengubah hasil dari rancangan system menjadi bentuk nyata, dalam hal ini berupa aplikasi game yang berjalan pada platform desktop computer.

Aplikasi ini dibuat menggunakan Game Engine Unity 3D. Saat akan menjalankan aplikasi ini, pada tampilan awal game akan muncul gambar logo Unity dan gambar logo dari Fakultas Teknik Unsrat sebagai Splash Screen awal aplikasi. Kemudian setelah itu scene langsung berpindah pada tampilan Menu utama game dimana terdapat Judul Game yaitu Pengenalan Pahlawan Sulawesi Utara. Terdapat 3 tombol utama dalam scene Menu yaitu Mulai untuk memulaikan game dan memilih pahlawan, selanjutnya tombol info untuk mengetahui cara bermain game, dan tombol keluar untuk berhenti bermain.

Pada scene Menu utama ketika pemain memilih menjalankan game dengan memilih tombol mulai, maka pemain akan di berikan pilihan untuk memilih Pahlawan mana yang akan dilihat. Setelah memilih pahlawan maka scene langsung akan berpindah pada scene permainan puzzle.

Scene pilih Pahlawan terdapat 5 Pahlawan yaitu :

1. Maria Walanda Maramis

2. Arie F. Lasut

3. Robert Wolter Mongisidi

4. Jahja Daniel Darma (John Lie)

5. Dr. Samuel Ratulangi (Sam Ratulangi)

\section{- $\quad$ Scene Permainan M.W Maramis}

Jika pemain memilih tombol Pahlawan M.W Maramis maka akan muncul scene permainan. Pada scene permainan, pemain dapat langsung menyusun puzzle, dengan mengambil atau mendrag kepingan puzzle ke dalam kotak susunan puzzle.Puzzle ini berukuran 3x3.

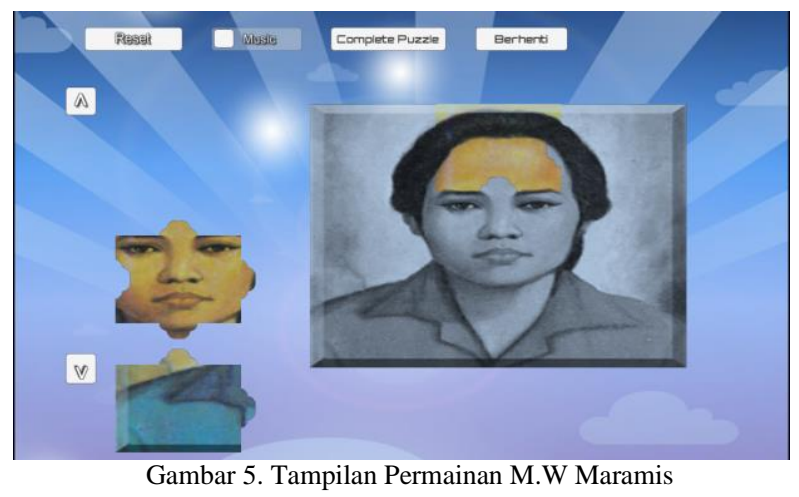

Pada gambar 5 kita dapat melihat tampilan puzzle dari Pahlawan Maria Walanda Maramis, diatas kotak puzzle terdapat beberapa tombol yaitu Reset untuk mengatur kembali kepingan puzzle, tombol Music untuk mengaktifkan atau menonaktifkan suara music, kemudian tombol Complete Puzzle dimana pada saat pemain menekan tombol tersebut maka puzzle akan tersusun utuh dan tombol berhenti, apabila pemain ingin berhenti atau tidak dapat melanjutkan permainan maka jika pemain menekan tombol berhenti system akan langsung berpindah scene kembali ke Menu utama.

Di bagian kiri tampilan scene puzzle terdapat kepingan puzzle yang nantinya akan di seret ke kotak puzzle. Pemain dapat memilih secara acak kepingan puzzle mana yang akan diambil dan diletakkan dalam kotak puzzle Pahlawan Maria Walanda Maramis. Caranya yaitu mengambil salah satu kepingan puzzle dan meletakkan dalam kotak puzzle ke bagian puzzle yang sama dengan kepingan puzzle yang di ambil, apabila benar kepingan tersebut adalah bagian dari puzzle maka kepingan akan bersatu dengan kotak puzzle, jika salah maka pemain akan di berikan peringatan melalui warna merah apabila salah meletakan kepingan puzzle dan kepingan puzzle akan terlepas dan kembali ke tempat semula di bagian kiri kotak puzzle. Karena puzzle berukuran 3x3 maka kepingan puzzle yang ada di bagian kiri berjumlah 9 potong.

Dapat dilihat juga disamping kepingan puzzle ada button up dan button down untuk mengarahkan kepingan puzzle kearah atas atau kearah bawah, button bersifat manual jadi pemain harus menekan button up untuk mengarahkan kepingan puzzle agar bergerak ke atas dan juga pemain harus menekan button down agar kepingan puzzle bergerak ke bawah.

Saat pemain telah menyelesaikan susunan puzzle maka akan dengan otomatis muncul scene tampilan Info Pahlawan atau Profil Pahlawan.

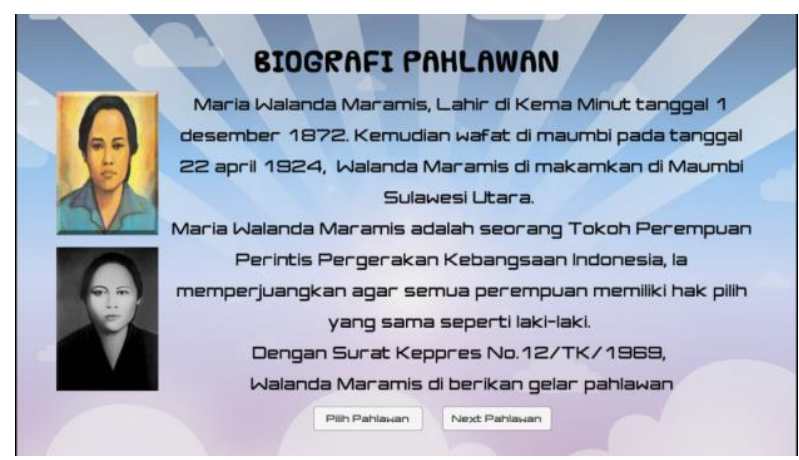

Gambar 6. Tampilan Info Pahlawan M.W Maramis 
Seperti pada gambar 6 kita dapat melihat Biografi Pahlawan berupa nama lengkap Pahlawan, Tempat kelahiran dan Wafat Pahlawan, sekilas tentang perjuangan pahlawan Maria Walanda Maramis sebagai Tokoh Emansipasi Wanita di Sulawesi Utara, kemudian nomor surat keputusan presiden atas pemberian gelar Pahlawan kepada Maria Walanda Maramis.

Dibawah Biografi Pahlawan terdapat 2 tombol yaitu Pilih Pahlawan dan Next Pahlawan. Apabila pemain memilih tombol Pilih Pahlawan maka scene akan berpindah pada tampilan Pilih Pahlawan dan jika pemain memilih tombol Next Pahlawan maka scene akan berpindah ke tampilan permainan puzzle Pahlawan berikutnya.

\section{- $\quad$ Scene Permainan Sam Ratulangi}

Jika pemain memilih tombol Pahlawan Sam Ratulangi maka akan muncul scene permainan. Pada scene permainan, pemain dapat langsung menyusun puzzle, dengan mengambil atau mendrag kepingan puzzle ke dalam kotak susunan puzzle. Tampilan puzzle ini berukuran 5x5.

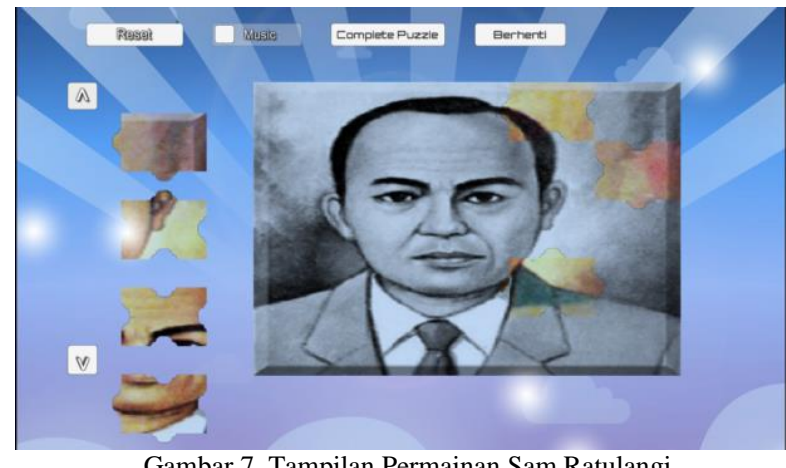

Gambar 7. Tampilan Permainan Sam Ratulangi

Tampilan Puzzle gambar 7 sama seperti tampilan puzzle pada gambar 5 dimana pada bagian atas kotak puzzle terdapat tombol Reset, Music, Complete Puzzle dan Berhenti.

Kemudian di bagian kiri juga terdapat kepingan puzzle. Bedanya karena puzzle ini berukuran 5x5 maka kepingan atau potongan puzzle yang ada di bagian kiri berjumlah 25 potong. Cara memainkannya pula sama seperti pada gambar 5 , pemain dapat memilih secara acak kepingan mana yang akan di ambil dan di letakan pada kotak puzzle. Disamping kepingan puzzle juga terdapat button up dan button down. Saat pemain telah menyelesaikan susunan puzzle maka akan dengan otomatis muncul scene tampilan Info Pahlawan atau Profil Pahlawan.

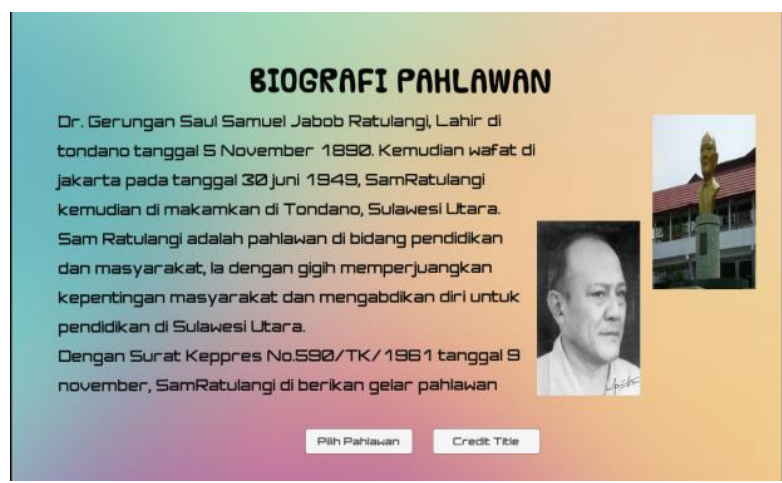

Gambar 8. Tampilan Info Pahlawan Sam Ratulangi
Selanjutnya pada gambar 8 merupakan tampilan Biografi Pahlawan Sam Ratulangi, di bagian bawah terdapat tombol Pilih Pahlawan dan juga terdapat tombol credit title pada bagian akhir puzzle sebagai ungkapan terima kasih karena telah menggunakan game ini sebagai alat peraga digital.

\section{B. Testing}

\section{BlackBox Testing}

Pengujian yang dilakukan adalah pengujian blackbox untuk mengetahui kesalahan-kesalahan apa yang terdapat pada antar muka permainan. Pengujian dilakukan terhadap beberapa feature yang sudah ditetapkan.

Tabel 1. Blackbox Testing

\begin{tabular}{|c|c|c|c|}
\hline Feature & Expected Result & $\begin{array}{c}\text { Met } \\
\text { Expectation }\end{array}$ & Comment \\
\hline Story & $\begin{array}{c}\text { Pemain dapat } \\
\text { melihat alur cerita } \\
\text { sebelum } \\
\text { permainan dimulai }\end{array}$ & No & $\begin{array}{c}\text { Dapat } \\
\text { dikembangkan } \\
\text { selanjutnya }\end{array}$ \\
\hline $\begin{array}{l}\text { Play } \\
\text { Game }\end{array}$ & $\begin{array}{c}\text { Pemain dapat } \\
\text { memulai } \\
\text { permainan }\end{array}$ & Yes & - \\
\hline Stage & $\begin{array}{l}\text { Pemain dapat } \\
\text { memainkan } \\
\text { permainan dengan } \\
\text { tingkatan level } \\
\text { (Piece Puzzle) }\end{array}$ & Yes & $\begin{array}{c}\text { Level yang ada } \\
\text { perlu } \\
\text { ditambahkan } \\
\text { dengan } \\
\text { tingkatan yang } \\
\text { lebih sulit dan } \\
\text { menantang }\end{array}$ \\
\hline $\begin{array}{l}\text { Result } \\
\text { Screen }\end{array}$ & $\begin{array}{c}\text { Pemain dapat } \\
\text { melihat info } \\
\text { pahlawan di akhir } \\
\text { dari permainan }\end{array}$ & Yes & - \\
\hline $\begin{array}{l}\text { Achiev } \\
\text { ment }\end{array}$ & $\begin{array}{c}\text { Pemain dapat } \\
\text { melihat apa saja } \\
\text { yang sudah diraih } \\
\text { dalam permainan }\end{array}$ & No & $\begin{array}{c}\text { Perancangan } \\
\text { permainan tidak } \\
\text { menggunakan } \\
\text { skor jadi tidak } \\
\text { mengadakan } \\
\text { fitur achievment }\end{array}$ \\
\hline $\begin{array}{l}\text { Pause } \\
\text { Game }\end{array}$ & $\begin{array}{c}\text { Pemain dapat } \\
\text { menghentikan } \\
\text { permainan saat } \\
\text { permainan } \\
\text { berlangsung }\end{array}$ & No & $\begin{array}{c}\text { Permainan } \\
\text { tidak } \\
\text { membutuhkan } \\
\text { waktu yang } \\
\text { lama jadi fitur } \\
\text { pause tidak } \\
\text { terlalu } \\
\text { dibutuhkan }\end{array}$ \\
\hline
\end{tabular}

Dalam pengujian blackbox testing ada beberapa pengujian feature yang dilakukan, misalnya :

\section{- Stage Game}

Pemain dapat memainkan permainan dengan tingkatan level ( Piece Puzzle), Pada Met Expectation di berikan keterangan Yes, karena pada aplikasi stage yang digunakan adalah berupa tingkatan level atau jumlah piece yang berbeda setiap gamenya.

- Story

Met Expectation dalam fitur story ini belum tercapai karena pada aplikasi tidak memerlukan story atau alur cerita permainan sebelum memulaikan permainan. 


\section{Evaluasi Penguna}

Evaluasi Pengguna dilaksanakan dengan membagikan kuisioner yang berisikan 2 pertanyaan kepada 10 orang responden yang telah memainkan prototipe alat peraga pengenalan Pahlawan.

a) Apakah Alat Peraga Pahlawan dengan model game mudah untuk dimainkan?

Tabel 2. Hasil Evaluasi Pengguna Terhadap Tingkat Kesulitan Permainan

\begin{tabular}{|c|c|c|}
\hline & Jumlah Responden & Presentase \\
\hline Cukup Mudah & 8 & $80 \%$ \\
\hline Sulit & 2 & $20 \%$ \\
\hline
\end{tabular}

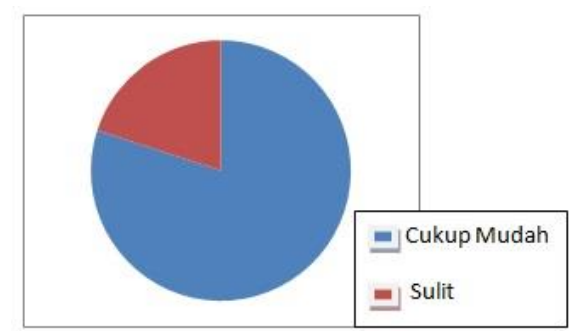

Gambar 9. Hasil Evaluasi Pengguna Terhadap Tingkat kesulitan permainan

Dari hasil evaluasi responden pada gambar 9 maka didapat 2 responden yang mengatakan bahwa tingkat kesulitan permainan sulit dan 8 lainnya mengatakan cukup mudah.

b) Apakah dengan adanya alat peraga ini dapat meningkatkan pengetahuan tentang pahlawan Sulawesi utara?

Tabel 3. Hasil Evaluasi Pengguna Terhadap Pengetahuan yang didapat

\begin{tabular}{|c|c|c|}
\hline & Jumlah Responden & Presentase \\
\hline Ya & 10 & $100 \%$ \\
\hline Tidak & 0 & $0 \%$ \\
\hline
\end{tabular}

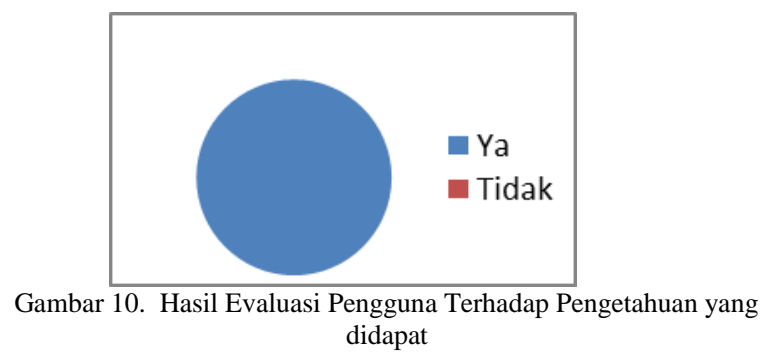

Dari hasil diagram gambar 10 maka dapat disimpulkan bahwa setelah memainkan permainan ini tingkat pengetahuan responden tentang pahlawan meningkat.

\section{PENUTUP}

A. Kesimpulan

1. Telah dihasilkan alat peraga digital dalam bentuk permainan puzzle yang berisi 5 orang pahlawan Sulawesi Utara beserta biografi pahlawan tersebut.

2. Dengan alat peraga digital dalam bentuk permainan ini, anak-anak telah dapat mengenal tentang pahlawan dari Sulawesi Utara. Hal ini dapat di buktikan oleh peserta anak-anak sebelum memainkan permainan ini tidak mengenal pahlawan tetapi setelah memainkannya peserta ternyata dapat menyebut nama-nama pahlawan.

\section{B. Saran}

Untuk menyempurnakan alat peraga berbentuk permainan yang telah dibuat ini agar dapat lebih baik lagi dan dapat dipublikasikan secara global maka perlu dilakukan pengembangan lebih lanjut, antara lain dengan mengembangkan permainan agar memiliki lebih banyak level, supaya permainan tidak terkesan terlalu mudah.

\section{REFERENSI}

[1] Booch, G. 1999. Visual Modeling With Rasional Rose 2000 And UML.

[2] Marini, M.Pd. 2010. Pengembangan Alat Peraga Edukatif

[3] Mirnawati. 2010. Kumpulan Pahlawan Indonesia Terlengkap. Bandung : Gramedia.

[4] Pressman, R. S. 2010. Rekayasa Perangkat Lunak Pendekatan Praktisi. Edisi 7: Penerbit Andi, Yogyakarta.

[5] Roedavan. R. 2014. Unity Tutorial Game Engine. Penerbit Informatika. Bandung.

[6] Suryanto, M. 2004. Analisis dan Desain Aplikasi Multimedia. Yogyakarta : Penerbit Andi Offset

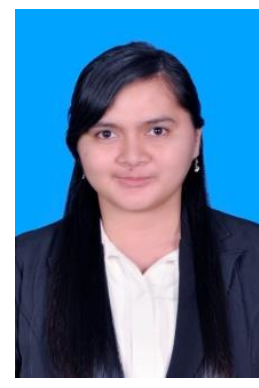

Sekilas dari penulis dengan nama lengkap Feiby Marlin Pongoh lahir pada tanggal 27 Februari 1993 di Manado. Dengan pendidikan pertama di Taman Kanak-Kanak Tabita Manado, kemudian melanjutkan ke SD Gmim 19 Manado, melanjutkan ke SMP Negeri 2 Manado. Pada tahun 2007 melanjutkan ke SMK Negeri 3 Manado. Setelah lulus sekolah tingkat atas pada tahun 2010 penulis melanjutkan ke Perguruan Tinggi tepatnya di Universitas Sam Ratulangi Manado, Fakultas Teknik, Jurusan Elektro, Program Studi Teknik Informatika. Penulis membuat skripsi untuk memenuhi syarat sarjana (S1) dengan judul Alat Peraga Digital Pengenalan Pahlawan Sulawesi Utara yang di bimbing oleh dua dosen Teknik Informatika yaitu Alicia A. E. Sinsuw,ST.MT dan Virginia Tulenan, S.Kom, MTI sehingga pada tanggal 6 April 2016 penulis resmi lulus di Teknik Informatika Universitas Sam Ratulangi Manado. 